\title{
OPERAÇÃO TERAPIA COMUNITÁRIA NO DESLIZAMENTO DE TERRA NA BAIXADA SANTISTA
}

\author{
OPERACIÓN TERAPIA COMUNITARIA EN EL DESLIZAMIENTO DEL SUELO EN \\ LA BAIXADA SANTISTA
}

\section{COMMUNITY THERAPY OPERATION ON THE LANDSLIDE AREA IN BAIXADA} SANTISTA

\author{
Doralice OTAVIANO ${ }^{1}$ \\ Jurema Valkiria OTAVIANO ${ }^{2}$
}

RESUMO: Na madrugada de 3 de março de 2020, houve um deslizamento de terra na Baixada Santista após grande volume de chuva, deixando 45 pessoas mortas e muitas outras desabrigadas. A Associação Brasileira de Terapia Comunitária (ABRATECOM) fez uma mobilização com os associados dos polos próximos ao acidente, sendo o "Instituto Afinando a Vida (IAV)" e o "CAIFCOM/Santos", os quais se responsabilizaram em recolher doações e fazer rodas de terapia comunitária para acolher os desabrigados dessa tragédia. Esse trabalho foi desenvolvido em dois finais de semana, por 15 terapeutas comunitários das cidades de São Paulo e Santos, que realizaram rodas de terapia comunitária para os sobreviventes nos albergues e comunidades.

PALAVRAS-CHAVE: Terapia comunitária. Deslizamento de terra. Baixada Santista.

RESUMEN: En la madrugada de 3 de marzo de 2020, hubo un deslizamiento del suelo en la Baixada Santista después de una fuerte lluvia, dejando 45 personas muertas y muchas otras desabrigadas. La Asociación Brasileña de Terapia Comunitaria (ABRATECOM) realizó una movilización con los asociados de los polos cercanos al accidente, siendo el Instituto Afinado la Vida y CAIFCOM/Santos, los cuales fueron responsables en recoger donaciones y hacer el circulo de terapia comunitaria para acoger a las personas sin abrigo involucradas de esa tragedia. Ese trabajo fue desarrollado durante dos fines de semana, por 15 terapeutas comunitarios de las ciudades de San Pablo y Santos, que realizaron los círculos de terapia comunitaria para las personas sobrevivientes que se encuentran en los albergues y en las comunidades.

PALABRAS CLAVE: Terapia comunitaria. Deslizamiento del suelo. Baixada Santista.

\footnotetext{
${ }^{1}$ Associação Paulista para o Desenvolvimento da Medicina - Hospital São Paulo SPDM/HSP, São Paulo - SP Brasil. Psicóloga no programa Recomeço Família e Coordenadora do curso de Terapia Comunitária no Instituto Afinando Vidas. Doutora em Terapia Familiar pela International Corporate University (I.C.U./CAIFCOM). ORCID: https://orcid.org/0000-0002-6099-6765. E-mail: doramusicoterapia.otaviano@gmail.com

${ }^{2}$ Instituto Afinando Vidas, São Paulo - SP - Brasil. Terapeuta Comunitária. Mestrado em Bioética (USC). ORCID: http://orcid.org/0000-0002-1999-2308. E-mail: arvoregrande2000@yahoo.com.br 
ABSTRACT: In the early morning of March 3, 2020, there was a landslide in Baixada Santista after heavy rainfall, causing the death of 45 people and many others. The Brazilian Association of Community Therapy (ABRATECOM) mobilized with the members of the centers near the accident, the "Instituto Afinando a Vida (IAV)" and the "CAIFCOM/Santos", who were responsible for collecting donations and making community therapy circles to welcome the homeless of this tragedy. This work was developed over two weekends by 15 community therapists from the cities of São Paulo and Santos, who held community therapy circles for survivors in the hostels and communities.

KEYWORDS: Community therapy. Landsliding. Baixada Santista.

\section{Introdução}

Na madrugada do dia 3 março de 2020, uma tragédia sem precedentes abalou a Baixada Santista. Quarenta e cinco pessoas morreram após deslizamentos de terra provocados por fortes chuvas, sendo esse número mais que o dobro de mortes causadas pelo rompimento da barragem de Mariana, em 2015. As cidades mais atingidas foram Guarujá, Santos e São Vicente, onde centenas de pessoas ficaram desabrigadas.

O cenário caótico e o sofrimento das pessoas nos sensibilizaram e dois dias depois, criamos uma rede de voluntários, com três instituições, para amparar os desabrigados por meio da Terapia Comunitária Integrativa (TCI). A Abratecom (Associação Brasileira de Terapia Comunitária) cobriu os custos da viagem e deu apoio moral. O Instituto Caifcom de Santos fez contatos com os desabrigados locais e ofereceu as rodas de terapia comunitária integrativa, enquanto o Instituto Afinando a Vida (IAV) mobilizou os terapeutas comunitários que foram de São Paulo para a Baixada realizar as rodas.

Organizamo-nos em dois sábados (07 e 14 de março) para desenvolver as rodas de TCI, no primeiro encontro, estávamos em cinco pessoas e no segundo, em doze. Aproveitamos essas oportunidades para fazer muitas doações de roupas, fraldas, mamadeiras e até contribuições em dinheiro.

Realizamos seis rodas de terapia comunitária integrativa em três lugares diferentes, após os encontros tivemos a impressão de que as famílias já estavam aquietando suas mentes, percebendo a rede de apoio, criando novas estratégias para lidar com os problemas, ponderando as perdas e ganhos e alimentando a esperança de que dias melhores virão. Um dos desabrigados expressou, por exemplo, o quanto se sentia aliviado e seguro por estar naquele espaço e por ter conseguido salvar sua mãe, que havia ficado entre os escombros.

Cada roda tinha seu próprio mote, que era escolhido pelos participantes, como "quando nossa cabeça está cheia de problemas, o que devemos fazer para ficarmos mais serenos?; quem 
já perdeu alguma coisa, o que fez para encontrá-la ou substituí-la?; quem já se sentiu paralisado por uma situação, o que fez para sair deste lugar?; e, alguém já se sentiu incomodado por depender de alguém ou de alguma coisa?". Dessa forma, as perguntas guiavam a conversa e auxiliavam na busca por soluções, como ter o apoio de amigos, exercitar a fé, procurar estudar e fazer uma coisa de cada vez, sendo essas algumas das alternativas encontradas nas respostas de cada grupo.

Em um dos grupos, um participante estava muito preocupado por estar desempregado, ele relatou que é comum, na Baixada Santista, trabalhadores serem acionados para empregos temporários e depois ficarem "a ver navios", sem receber o salário. A situação comoveu as outras pessoas. O protagonista da roda disse que tinha raiva por ser enganado, isso já havia acontecido outras vezes, com isso o mote apresentado ao grupo foi: “quem já se sentiu traído e o que fez para superar ou lidar com isso?".

Em alguns momentos, os participantes demoravam em se conectar com suas questões íntimas. A instabilidade emocional das pessoas era perceptível, então era necessário fazer um breve relaxamento a partir da respiração. Em outro momento percebeu-se que foi fundamental usar música, pois um dos encontros começou com a apresentação de um coral que compartilhou canções populares para o universo infantil e adulto, proporcionando relaxamento e leveza. A música é um instrumento potente, contribui na expressão e elaboração das emoções e é muito usada na técnica da Terapia Comunitária Integrativa (TCI), desse modo a música veio ao encontro de nossos objetivos, dando espaço para o momento das celebrações.

Celebrar o futuro também foi um recurso usado durante as rodas, principalmente naquelas formadas por crianças, as quais diziam querer uma casa nova, ter uma mansão, ser bombeiro, advogado, pastor, casar e ter filhos, ter uma quadra de futebol, ter uma televisão que passe desenhos, esses eram alguns sonhos que os pequenos da Baixada relataram na terapia. No início, encontramos as crianças um pouco agitadas, festivas, algumas agressivas (por uma questão estrutural) e muito curiosas, procuramos fazer as etapas da roda com o cuidado de esperar o tempo necessário para que todos compreendessem as questões.

As conversas impactaram não só os desabrigados como os próprios terapeutas comunitários. A terapeuta comunitária Janifer, por exemplo, contou ter ficado receosa com o que iria encontrar na Baixada, "reparei-me durante toda a semana para o que poderia encontrar naquele lugar, fui apreensiva, com medo de deparar-me com tanto sofrimento e só imaginava o que aquelas pessoas estariam passando". Ainda disse que a experiência foi completamente diferente do que havia imaginado, "surpreendi-me com tanta luta, espírito de união e recomeço que aquelas pessoas demonstravam", além das crianças darem um "show de entendimento" 
sobre o que estavam passando, "elas começaram agitadas, mas aos poucos foram entrando no clima da roda, pedindo brincadeiras e contando sobre o sonho de ter uma casa nova, num lugar melhor, sem traumas e desespero".

Assim como Janifer, a terapeuta comunitária e irmã de caridade Lucia Marques, também teve momentos de incertezas sobre o que encontraria durante as rodas de conversa

eu perguntava-me o que fazer? e a resposta me foi dada como aquela que Jesus deu a um certo homem: ame ao Senhor teu Deus com todo o teu coração, com toda a tua alma, com todo o teu entendimento e com toda a tua força, e ame ao teu próximo como a ti mesmo; não existe outro maior e nem mais importante.

A tecnóloga e terapeuta comunitária Jurema Otaviano, classificou a atividade como uma "experiência necessária" e disse ter aprendido que "conceitos opostos, como força e vulnerabilidade estão intimamente ligados; o quanto a disposição de doação leva-nos a outras dimensões de cidadania, alteridade e inteligência coletiva”.

A psicóloga e terapeuta comunitária Neusa, disse que a oportunidade de atuar na Baixada Santista foi um "chamado" e acrescenta: "esta é minha disponibilidade interna; contribuir com o outro faz parte de minha essência, tanto que minha primeira profissão foi Serviço Social e nesta prática acompanhei várias situações emergenciais”. Comenta ainda que "nas situações de sofrimento as pessoas tendem a ser mais solidárias, porém observa que conflitos também se estabelecem, principalmente em função da necessidade em conviverem juntas, por isso é imprescindível o estabelecimento de acordos que acolham as demandas de todos os envolvidos".

O engenheiro e terapeuta comunitário Reginaldo, afirmou que a rede de apoio "faz os atingidos terem uma perspectiva melhor sobre seu futuro", destaca ainda que foi importante equipamentos públicos e associação de amigos disponibilizarem abrigo e alimento, além de pessoas e empresas terem doado gêneros de primeira necessidade.

O psicólogo e terapeuta comunitário André Luiz, comenta que "acolhimento é a palavrachave", avaliou que os espaços foram usados de forma madura e consciente, logo se sentiu grato por ter participado como terapeuta. Ressalta ainda "ter percebido que alimento e ajuda material eles recebem. Mas e o emocional? O abraço? O ombro? Levamos, pois estávamos 100\% focados!”.

A psicóloga Fernanda Vieira, também atuou como terapeuta comunitária. Ela destacou alguns relatos das vítimas dos deslizamentos: 
foram momentos de desespero, de gritos, de incerteza se continuariam vivos, as crianças choravam; os moradores viram as casas vizinhas sendo levadas pela lama. Ao ocorrer o desmoronamento, o barulho foi tão grande e estrondoso, parecendo que o morro todo estava indo abaixo, as casas que sobraram, tremeram quando a avalanche passou levando tudo que havia no caminho: sonhos, bens materiais e documentos.

Fernanda comentou que apesar das histórias de dor e sofrimento, carrega consigo uma sensação de "leveza e coração grato" por ter colaborado para o cuidado das vítimas do desastre da Baixada Santista, diante disso, lembrou que durante as rodas de terapia comunitária havia sempre uma homenagem para os aniversariantes do dia "um gesto simples, porém profundo que abre os nossos olhos para a importância de celebrarmos a vida".

Nesse sentindo, a Terapia Comunitária Integrativa (TCI) é uma prática 100\% brasileira, criada há 28 anos pelo médico psiquiatra Dr. Adalberto Barreto, na tentativa de diálogo entre o conhecimento científico e a sabedoria popular, onde sua inovação dá-se através da busca de soluções para conflitos e sofrimentos humanos. Essa técnica pode ser utilizada nas comunidades, bairros, escolas, equipes de trabalho, empresas em diferentes contextos e cenários, como exemplo catástrofes.

Terapeutas comunitários que participaram dessa ação de cuidado para com os sobreviventes do desastre natural na Baixada Santista: André Luiz (TC-Psicólogo), Doralice Otaviano (TC-Psicóloga), Jurema Otaviano (TC-Tecnóloga), Pilar (TC-Assistente Social), Angela (TC), Neusa (TC-Psicóloga), Reginaldo (TC-Engenheiro), Renato (TC-Médico), Janifer (TC), Cecília (TC), Lucia Marques (TC- Irmã de Caridade), Fernanda (TC-Psicóloga) e Gleisi (Apoiadora).

\section{REFERÊNCIAS}

AMADOR, S. M. A Terapia Comunitária e sua origem. Ser Melhor, São Paulo. Disponível em: http://www.sermelhor.com.br/saude/a-terapia-comunitaria-e-sua-origem.html. Acesso em: 25 abr. 2020.

G1 SANTOS. Buscas por vítimas de deslizamentos são encerradas em Santos e São Vicente; operação segue em Guarujá. G1, Santos, 07 mar. 2020. Disponível em:

https://g1.globo.com/sp/santos-regiao/noticia/2020/03/07/buscas-por-sobreviventes-nabaixada-santista-sabado.ghtml>. Acesso em: 26 abr. 2020 .

G1 SANTOS. Veja quem são os mortos pela chuva que atingiu a Baixada Santista. G1, Santos, 03 mar. 2020. Disponível em: https://g1.globo.com/sp/santosregiao/noticia/2020/03/03/veja-quem-sao-as-vitimas-do-temporal-que-atinge-a-baixadasantista.ghtml. Acesso em: 26 abr. 2020. 


\section{Como referenciar este artigo}

OTAVIANO, D.; OTAVIANO, J. V. Operação terapia comunitária no deslizamento de terra na Baixada Santista. Temas em Educ. e Saúde, Araraquara, v. 16, n. esp. 1, p. 477-482, set., 2020. e-ISSN 2526-3471. DOI: https://doi.org/10.26673/tes.v16iesp.1.14312

Submetido em: 20/05/2020

Revisões requeridas: 30/05/2020

Aprovado em: 25/08/2020

Publicado em: 30/09/2020 